\title{
Model Pembelajaran Cycle 5E Berbantuan Media Video terhadap Sikap Sosial
}

\author{
I Putu Sabda Ramadinata1*, I Gd. Wawan Sudatha², Desak Pt. Parmiti ${ }^{3}$ \\ 1 Program Studi Pendidikan Guru Sekolah Dasar, FIP, Universitas Pendidikan Ganesha, Singaraja, Indonesia \\ 23 Program Studi Teknologi Pendidikan, FIP, Universitas Pendidikan Ganesha, Singaraja, Indonesia
}

\begin{abstract}
Abstrak
Penelitian ini bertujuan untuk menganalisis pengaruh model pembelajaran cycle $5 e$ berbantuan media video terhadap sikap sosial siswa kelas IV SD gugus V Kecamatan Melaya tahun pelajaran 2019/2020. Penelitian ini merupakan penelitian Kata Kunci: Cycle 5E, video, sikap sosial quasi experiment dengan desain non equivalent post-test only control group design. Populasi dalam penelitian ini adalah kelas IV SD di gugus V Kecamatan Melaya yang berjumlah 154 siswa. Sampel dalam penelitian ini diambil dengan teknik random sampling. Sampel dalam penelitian ini adalah kelas IV SDN 4 Tukadaya sebagai kelas eksperimen yang berjumlah 28 siswa dan kelas IV SDN 3 Tuwed sebagai kelompok kontrol yang berjumlah 32 siswa. Data sikap sosial siswa dikumpulkan menggunakan metode non tes dengan instrumen kuesioner. Data dianalisis dengan statistik deskriptif. Hasil penelitian menunjukkan bahwa terdapat pengaruh model pembelajaran cycle $5 e$ berbantuan media video terhadap sikap sosial siswa $\left(F_{\text {hitung }}=6,68>F_{\text {tabel }}=2.01\right)$. Berdasarkan temuan tersebut, dapat disimpulkan bahwa terdapat pengaruh signifikan model pembelajaran cycle $5 e$ berbantuan media video terhadap sikap sosial siswa.
\end{abstract}

\begin{abstract}
This study aims to know the influence of the Learning Cycle 5E model assisted by video media on social attitude of the fourth grade elementary school students in

Keywords:

Cycle 5E, video, social experimental study with a non-post-test only control group design. The population in this study was grade IV elementary school in cluster V of Melaya District, which was joined by 154 students. The sample in this study was taken by random sampling technique. The sample in this study was class IV SDN 4 Tukadaya as an experimental class supporting 28 students and class IV SDN 3 Tuwed as a control group that captured 32 students. Data on students' social attitudes were collected using a nontest method with a questionnaire instrument. Data were analyzed with descriptive statistics. The results showed what is meant by the $5 \mathrm{e}$ cycle learning model assisted by video media on students' social attitudes $\left(\mathrm{F}_{\text {count }}=6.68>\mathrm{F}_{\text {table }}=\right.$ 2.01). Based on these findings, it can be concluded that there is an influence of the Learning Cycle 5E learning model assisted by video media on students' social attitudes.
\end{abstract}

\footnotetext{
* Corresponding author.

E-mail Addresses: sabdaramadinata2@gmail.com (I Putu Sabda Ramadinata)
} 


\section{PENDAHULUAN}

Dalam memajukan kehidupan bangsa, sikap memiliki peranan yang sangat penting. Dengan adanya sikap, manusia dapat mengontrol dirinya sendiri maupun dalam bersosialisasi di masyarakat (Virani, 2016). Melihat pentingnya penanaman sikap untuk menjadikan generasi penerus bangsa sebagai generasi yang bermartabat baik, maka pemerintah memperhatikan aspek sikap dalam pendidikan dengan menerapkan kurikulum 2013 untuk semua jenjang pendidikan (Sanjiwana, dkk, 2015).

Penerapan kurikulum 2013 ditujukan dapat merubah sikap siswa menjadi lebih baik, sehingga dapat menjadikan siswa memiliki karakter yang baik (Supriyana, 2020). Dalam meningkatkan karakter tentunya hal yang harus diperhatikan yaitu sikap siswa, salah satunya adalah sikap sosial siswa, Ahmadi (2007) menyatakan bahwa sesuatu kesadaran pribadi untuk melakukan perbuatan tertentu yang dilakukan secara terus menerus. Dalam meningkatkan sikap sosial siswa diharapkan dapat mewujudkan siswa yang memiliki perilaku jujur, memiliki prilaku disiplin, memiliki tanggung jawab, memiliki kesantunan, memiliki sikap percaya diri, dan memiliki sikap peduli (Virani, 2016).

Dengan peningkatan sikap sosial maka diharapkan siswa dapat berinteraksi dengan warga sekolah. Sikap sosial yang bagus akan dapat memelihara hubungan yang harmonis dengan orang lain (Suartini, dkk, 2014). Memiliki sikap sosial yang baik dapat memudahkan kita dalam beradaptasi dengan lingkungan yang baru. Serta adanya sikap sosial dapat dijadikan bekal dalam menjalani kehidupan seharihari di lingkungan masyarakat.

Tetapi pada kenyataannya, berdasarkan hasil wawancara, observasi, dan pencatatan dokumen yang dilaksanakan pada Rabu, 23 Oktober 2019 sampai dengan Sabtu, 26 Oktober 2019 di Gugus V Kecamatan Melaya Kabupaten Jembrana, terdapat berbagai permasalahan mengenai sikap sosial. Berdasarkan hasil wawancara yang dilakukan dengan beberapa guru kelas IV di gugus V Kecamatan Melaya, didapatkan informasi bahwa sikap sosial siswa sangat kurang. Kurangnya sikap sosial siswa dapat ditentukan dari beberapa aspek yakni jujur, disiplin, tanggung jawab, santun, peduli dan percaya diri. Berdasarkan hasil wawancara dikatakan bahwa siswa kurang jujur dalam mengerjakan ulangan, masih banyak siswa yang masih mencontek. Di samping itu, dikatakan oleh guru masih banyak siswa yang tidak mengerjakan PR dan pada saat pagi hari piket kelas hanya sebagian saja yang bersih-bersih. Selain itu, sikap peduli siswa juga masih rendah, karena guru mengatakan bahwa masih banyak siswa perhitungan dalam memberi bantuan kepada teman yang sedang kesusahan.

Berdasarkan hasil observasi yang dilakukan terlihat siswa kurang disiplin saat pembelajaran berlangsung. Pada saat guru menjelaskan materi siswa asik berbicara dan saling mengganggu temannya sehingga kelas menjadi ribut. Pada saat salah satu siswa menanggapi suatu masalah yang diberikan guru, kebanyakan siswa tidak memperhatikan dan terkadang mengejek teman yang tidak bisa menjawab pertanyaan yang diberikan guru. Di samping itu, terlihat banyak siswa yang masih malu untuk menyampaikan pendapat maupun bertanya ketika proses pembelajaran. Kepercayaan diri siswa untuk menyampaikan pendapat masih kurang dalam pembelajaran. Di samping itu, guru menggunakan model pembelajaran yang kurang bervariasi sehingga siswa terlihat bosan dalam mengikuti pembelajaran.

Selain observasi dan wawancara, dilakukan pencatatan dokumen nilai UTS siswa kelas kelas IV SD Gugus V Kecamaatan Melaya. Dalam rata-rata nilai sikap sosial siswa kelas IV SD di Gugus V Kecamatan Melaya Tahun pelajaran 2019/2020 yang mencapai pencapaian minimal yaitu $46,42 \%$ dan rata-rata siswa yang belum mencapai pencapaian minimal yaitu 53,57\%. Melalui hasil pencatatan dokumen tersebut dapat diklasifikasikan bahwa nilai sikap sosial siswa kelas IV SD Gugus V Kecamatan Melaya masih rendah.

Agar dapat meningkatkan sikap sosial yang masih kurang, diperlukan kreativitas guru dalam membuat pembelajaran yang membuat siswa lebih aktif sehingga siswa dapat berdiskusi dan dapat memecahkan masalah secara bersama-sama (Wijayanti, dkk, 2018). Guru dapat menerapkan model pembelajaran menekankan penanaman sikap sosial siswa sehingga dapat ditingkatkan. Salah satu model pembelajaran yang dapat diterapkan untuk meningkatkan sikap sosial siswa adalah model pembelajaran cycle $5 \mathrm{e}$ berbantuan media video.

Noviantari (2015) menyatakan bahwa model pembelajaran learning cycle 5e suatu model pembelajaran yang memberikan kesempatan kepada siswa untuk menyampaikan pendapat ide atau gagasan yang dimiliki dalam pembelajaran. Model pembelajaran cycle 5E yaitu suatu model pembelajaran yang berpusat pada siswa (student centered) pembelajaran ini lebih menekankan siswa lebih aktif di dalam pembelajaran, siswa membangun, menemukan, dan menyelesaikan masalah dalam pembelajaran sedangkan guru menjadi fasilitator (Astuti dkk, 2019). Model pembelajaran ini merupakan rangkaian tahap-tahap kegiatan yang mengarahkan siswa untuk dapat lebih membangkitkan rasa keingintahuan siswa dan menambah pengetahuannya sendiri melalui diskusi, percobaan, pengalaman dan observasi sehingga siswa dapat lebih paham dan mengingat pengetahuan yang telah didapat. Model pembelajaran 
cycle 5e diperkuat dengan kajian relevan penelitian yang dilakukan oleh Setiawan dkk. (2017). Dalam Penelitian yang dilakukan diperoleh perbedaan hasil belajar antara kelompok siswa yang dibelajarkan dengan model pembelajaran learning cycle $5 e$ berbantuan mind mapping dengan kelompok siswa yang dibelajarkan dengan model pembelajaran konvensional. Hasil penelitian ini yaitu model pembelajaran learning cycle 5e berpengaruh terhadap hasil belajar siswa, Penerapan model pembelajaran cycle 5E terdapat masing-masing siklus belajar yang memberikan pengalaman belajar kepada siswa dalam membangun dan mengembangkan pengetahuan yang dimiliki siswa.

Penggunaan media dalam pembelajaran dipandang lebih efektif. Salah satu media yang dapat digunakan adalah media video untuk menyajikan materi (Tegeh dkk, 2019). Media video merupakan media pembelajaran yang tepat untuk digunakan dalam penelitian ini. Media video merupakan jenis dari media audio visual, menurut Tegeh (2015) media audio visual adalah media yang dapat dinikmati dengan indera pendengaran dan penglihatan, karena menghasilkan visual dan menghasilkan bunyi. Media video tentunya lebih mengkhusus dari media pembelajaran audio visual. Melalui penerapan Model cycle 5E Berbantuan media video dalam penelitian ini memberikan siswa pengalaman yang lebih dalam proses pembelajaran seperti siswa belajar berkelompok sehingga terjadinya interaksi. Pembelajaran yang berlangsung dengan menggunkan media video akan menjadi lebih menarik, menyenangkan, dan bermanfaat bagi pengembangan sikap sosial siswa. Selain itu, pemilihan video yang berkaitan dengan materi tentu akan mempermudah pemahaman siswa dalam menggambarkan apa yang disampaikan guru.

Tujuan dilakukannya penelitian ini adalah untuk mengetahui pengaruh yang signifikan model pembelajaran learnin cycle $5 e$ berbantuan media video terhadap sikap sosial pada siswa kelas IV SD Gugus V Kecamatan Melaya Tahun Pelajaran 2019/2020".

\section{METODE PENELITIAN}

Metode dalam penelitian ini adalah metode eksperimen dengan jenis penelitian eksperimen semu (quasi experiment) dengan desain yang digunakan adalah non equivalent posttest only control group design. Dalam desain penelitian ini, terdapat dua kelompok dalam penelitian, yaitu kelompok eksperimen dan kelompok kontrol. Kedua kelompok baik kelompok eksperimen maupun kontrol setelah mendapatkan pembelajaran selama beberapa pertemuan, sama-sama diberikan post-test berupa kuisioner sikap sosial siswa.

Populasi dalam penelitian ini adalah seluruh kelas IV Sekolah Dasar Gugus V Kecamatan Melaya Tahun Pelajaran 2019/2020. Pengambilan sampel dalam penelitian ini menggunakan teknik random sampling. Berdasarkan pengundian diperoleh sampel yaitu siswa kelas IV di SDN 4 Tukadaya sebagai kelompok eksperimen dan siswa kelas IV di SD Negeri 3 Tuwed sebagai kelompok kontrol.

Uji kesetaraan dilakukan untuk mengetahui kesetaraan populasi, populasi dengan ANAVA satu jalur. Berdasarkan hasil analisis ANAVA A pada taraf signifikasi 5\% yang dihitung dengan bantuan program computer SPSS Statistic 17.0, diperoleh nilai $\mathrm{F}_{\text {hitung }}$ sebesar 1,18 sedangkan nilai $\mathrm{F}_{\text {tabel }}$ sebesar

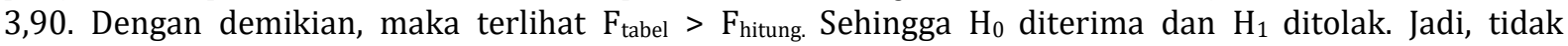
terdapat perbedaan yang signifikan sikap sosial siswa kelas IV SD Gugus V Kecamatan Melaya Tahun Pelajaran 2019/2020.

Jenis data yang diperlukan adalah data kuantitatif. Subjek data yang dikumpulkan pada penelitian ini adalah sikap sosial. Objek pengumpulan data dalam penelitian ini adalah siswa kelas IV SDN 4 Tukadaya dan siswa kelas IV SD Negeri 3 Tuwed. Teknik pengumpulan data dilakukan dengan pemberian instrumen berupa kuisioner. Pengujian instrumen meliputi uji validitas yang meliputi uji validitas isi dan validitas butir instrumen, serta uji reliabilitas.

Metode analisis data dalam penelitian ini meliputi analisis statistik deskriptif dan statistik inferensial. Analisis statistik deskriptif digunakan untuk mendeskripsikan kualitas variabel penelitian. Adapun analisis statistik deskriptif menampilkan mean, median, modus, standar deviasi, varians, range, nilai maksimum, nilai minimum, tabel distribusi frekuensi, dan grafik poligon. Sedangkan analisis statistik inferensial meliputi uji prasyarat dan uji hipotesis. Uji prasyarat meliputi uji normalitas dan homogenitas varians. Sedangkan uji hipotesis dalam penelitian ini menggunakan analisis uji-t dengan rumus polled varians. Rumus polled varians digunakan karena jumlah anggota sampel pada kelompok eksperimen dan kelompok kontrol tidak sama, serta varians homogen. 


\section{ANALISIS DAN PEMBAHASAN}

Data sikap sosial siswa diperoleh dari hasil post-test yang diberikan kepada kedua sampel penelitian. Hasil post-test terhadap kelompok eksperimen yaitu siswa kelas IV SDN 4 Tukadaya disajikan pada Tabel 1.

Tabel 1. Hasil Post-Test Kelompok Eksperimen

\begin{tabular}{lc}
\hline \multicolumn{1}{c}{ Keterangan } & Hasil \\
\hline $\mathrm{N}$ & 28 \\
Mean & 86,32 \\
Median & 87,00 \\
Modus & 88,31 \\
Standar Deviasi & 6,57 \\
Varians & 43,15 \\
Range & 29 \\
Minimum & 72 \\
Maksimum & 100 \\
\hline
\end{tabular}

Untuk mengetahui sebaran data sikap sosial siswa pada kelompok eksperimen, maka data disajikan ke dalam grafik poligon seperti berikut.

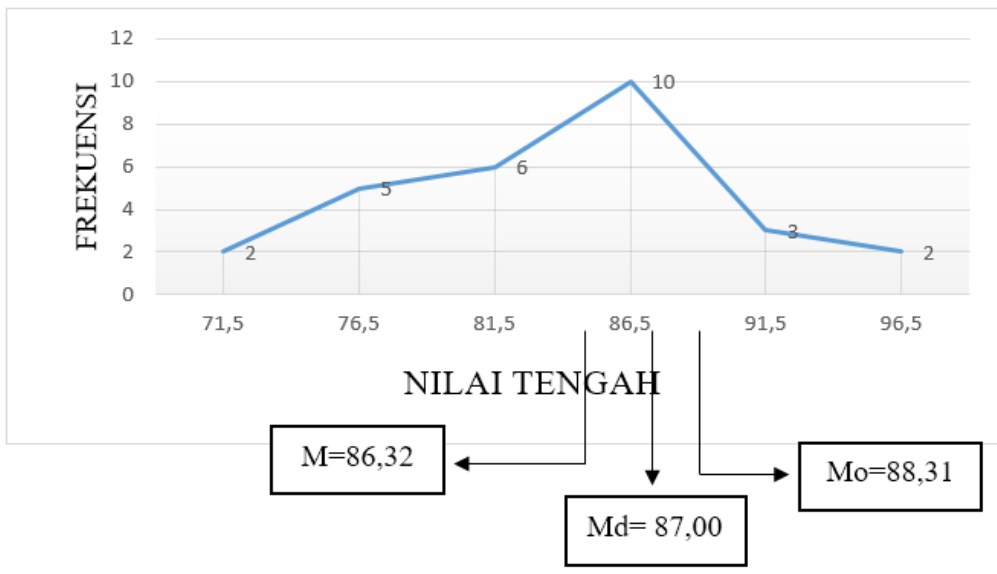

Gambar 1. Grafik Poligon Data Sikap Sosial Kelompok Eksperimen

Berdasarkan Gambar 1, dapat diketahui bahwa 2 orang siswa memiliki nilai antara 72-76, 5 orang siswa memiliki nilai antara 77-81, 6 orang siswa memiliki nilai antara 82-86, 10 orang siswa memiliki nilai antara 87-91, 3 orang siswa memiliki nilai antara 92-96, dan 2 orang siswa memiliki nilai antara 97101. Skor rata-rata sikap sosial siswa kelompok eksperimen adalah 86,32. Berdasarkan hasil konversi, disimpulkan bahwa rata-rata skor sikap sosial siswa kelompok eksperimen termasuk dalam kategori sangat tinggi.

Data sikap sosial siswa diperoleh dari hasil post-test yang diberikan kepada kedua sampel penelitian. Hasil post-test terhadap kelompok konstrol yaitu siswa kelas IV di SD Negeri 3 Tuwed disajikan pada Tabel 2.

Tabel 2. Hasil Post-Test Kelompok Kontrol

\begin{tabular}{lc}
\hline \multicolumn{1}{c}{ Keterangan } & Hasil \\
\hline $\mathrm{N}$ & 32 \\
Mean & $74,1$. \\
Median & 72,5 \\
Modus & 69 \\
Standar Deviasi & $7,59$. \\
Varians & 57,63
\end{tabular}




\begin{tabular}{lc}
\hline \multicolumn{1}{c}{ Keterangan } & Hasil \\
\hline Range & 30 \\
Minimum & 61 \\
Maksimum & 90 \\
\hline
\end{tabular}

Untuk mengetahui sebaran data sikap sosial pada kelompok kontrol, maka data disajikan ke dalam Gambar 2 poligon seperti berikut.

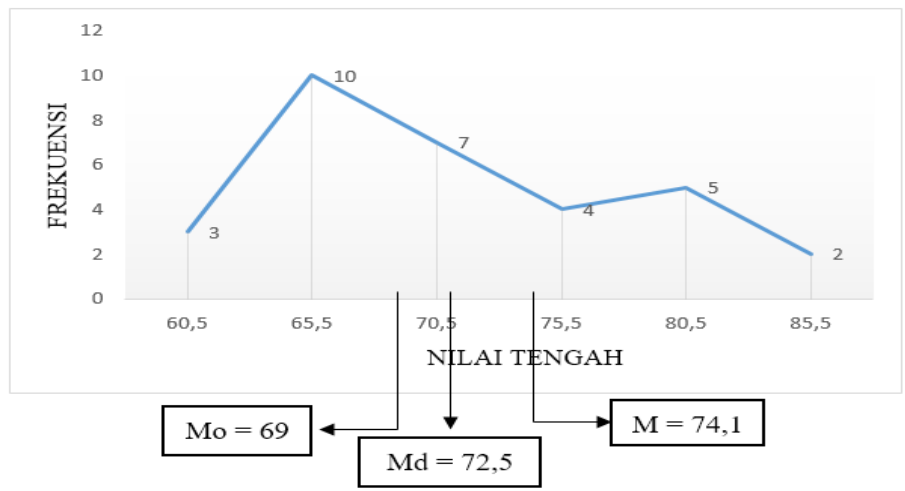

Gambar 2. Grafik Poligon Sikap Sosial Kelompok Kontrol

Berdasarkan Gambar di atas, dapat diketahui bahwa 3 orang siswa memiliki nilai antara 61-65, 10 orang siswa memiliki nilai antara $66-70,7$ orang siswa memiliki nilai antara $71-75,4$ orang siswa memiliki nilai antara 76-80, 5 orang siswa memiliki nilai antara 81-85, dan 2 orang siswa memiliki nilai antara 86-90. Skor rata-rata sikap sosial siswa kelompok kontrol adalah 74,1. Berdasarkan hasil konversi, disimpulkan bahwa rata-rata skor sikap sosial siswa kelompok kontrol termasuk dalam kategori tinggi.

Uji normalitas sebaran data dilakukan dengan menggunakan rumus Chi Kuadrat dengan kriteria pengujian data distribusi normal jika $\chi^{2}$ hitung $<\chi^{2}$ tabel pada taraf signifikansi $5 \%$ dan derajat kebebasan $\mathrm{dk}=$ (jumlah baris - 1). Berdasarkan analisis data yang dilakukan, dapat disajikan hasil uji normalitas sebaran data dengan menggunakan rumus Chi-Kuadrat pada kelompok eksperimen dan kelompok kontrol pada Tabel 3.

Tabel 3. Ringkasan Perhitungan Uji Normalitas

\begin{tabular}{lccc}
\hline \multicolumn{1}{c}{ Kelompok Data } & $\boldsymbol{\chi}^{\mathbf{2}}$ hitung & $\boldsymbol{\chi}^{\mathbf{2}}$ tabel & Keterangan \\
\hline Sikap sosial kelompok eksperimen & 1,325 & 7,815 & Normal \\
Sikap sosial kelompok kontrol & 5,399 & 7,815 & Normal \\
\hline
\end{tabular}

Berdasarkan Tabel 3, diperoleh harga $X^{2}$ hitung kelompok eksperimen adalah 1,325. Harga $X^{2}$ tabel pada taraf signifikansi $5 \%$ didapatkan 7,815, sehingga $X^{2}$ hitung lebih kecil dari $X^{2}$ tabel $(1,325<7,815)$. Sehingga data Sikap sosial kelompok eksperimen berdistribusi normal. Sedangkan harga $X^{2}$ hitung kelompok kontrol adalah 5,399. Harga $X^{2}$ tabel pada taraf signifikansi 5\% didapatkan 7,815, sehingga $X^{2}$ hitung lebih kecil dari $X^{2}$ tabel $(5,399<7,815)$. Sehingga data Sikap sosial kelompok kontrol berdistribusi normal.

Dalam uji homogenitas ditujukan terhadap pasangan antara kelompok eksperimen dan kelompok kontrol. Uji yang digunakan adalah uji-F dengan kriteria data homogen jika Fhitung $<\mathrm{F}_{\text {tabel. Adapun }}$ rangkuman hasil uji homogenitas varians antara kelompok eksperimen dan kontrol disajikan pada Tabel 4.

Tabel 4. Ringkasan hasil uji homogenitas varians

\begin{tabular}{lcccc}
\hline \multicolumn{1}{c}{ Kelompok Data } & Varians $\left(\mathbf{s}^{\mathbf{2}}\right)$ & $\mathbf{F}_{\text {hitung }}$ & $\mathbf{F}_{\text {tabel }}$ & Keterangan \\
\hline Sikap sosial kelompok eksperimen & 43,159 & \multirow{2}{*}{1,33} & \multirow{2}{*}{ Homogen } \\
Siakp sosial kelompok kontrol & 57,636 & & \\
\hline
\end{tabular}

Berdasarkan Tabel 4, didapatkan $F_{\text {hitung }}(1,33)<F_{\text {tabel }}(4,03)$, sehingga dapat disimpulkan varian data sikap sosial kelompok eksperimen dan kelompok kontrol adalah homogen. 
Berdasarkan uji normalitas sebaran data dan homogenitas varians diperoleh hasil bahwa data sikap sosial siswa kelompok eksperimen dan kelompok kontrol berdistribusi normal dan bersifat homogen.

Untuk menguji hipotesis yang telah dirumuskan dalam penelitian ini menggunakan uji-t polled varians. Berdasarkan hasil perhitungan, diperoleh $t_{\text {hitung }}=6,68$. Sedangkan $t_{\text {tabel }}$ dengan taraf signifikan $5 \%$ dengan $t_{\text {tabel }}$ adalah 2,01. Hal ini berarti bahwa $t_{\text {hitung }}>t_{\text {tabel }}(6,68>2.01)$, sehingga $H_{0}$ ditolak dan $H_{1}$ diterima. Sehingga disimpulkan terdapat pengaruh yang signifikan model pembelajaran cycle $5 e$ berbantuan media video terhadap sikap sosial siswa.

Berdasarkan data hasil penelitian, didapatkan hasil rata-rata nilai sikap sosial siswa yang mengikuti model pembelajaran cycle $5 e$ berbantuan media video sebesar 87,35. Sedangkan, siswa yang mengikuti pembelajaran yang di terapkan guru memperoleh nilai rata-rata 71. Hal ini menunjukkan sikap sosial kelompok siswa yang dibelajarkan dengan model pembelajaran Cycle 5 E lebih tinggi dibandingkan dengan kelompok siswa yang mengikuti pembelajaran yang di terapkan oleh guru.

Adanya perbedaan sikap sosial antara kelompok eksperimen dengan kelompok kontrol, disebabkan oleh perbedaan langkah-langkah pembelajaran, yang mana dalam langkah pembelajaran model Learning cycle 5e dapat membuat siswa aktif dalam pembelajaran. Penerapan model pembelajaran ini dapat meningkatkan keaktifan siswa dalam pembelajaran. Hal ini dapat terlihat ketika siswa bertanya, berdiskusi, dan menjawab pertanyaan dari guru. Sejalan dengan pendapat Astriani, dkk (2016) yang menyatakan bahwa model pembelajaran Learning cycle $5 e$ dapat mengingkatkan keaktifan siswa dalam belajar, sehingga dapat berkonsentrasi mengikuti pembelajaran. Keaktifan siswa dalam belajar tentu akan berdampak pada sikap sosial siswa yang meningkat karena dalam pembelajaran siswa selalu berkomunikasi atau berinteraksi baik dengan guru maupun dengan siswa yang lain.

Selain dengan pendapat pakar, hasil penelitian ini didukung dengan kajian relevan hasil penelitian yang dilakukan Setiawan, dkk (2017). Dalam Penelitian yang dilakukan diperoleh perbedaan hasil belajar antara kelompok siswa yang dibelajarkan dengan model pembelajaran learning cycle 5e berbantuan mind mapping dengan kelompok siswa yang dibelajarkan dengan model pembelajaran konvensional. Penelitian yang dilakukan oleh Asthira, dkk (2016) menunjukkan bahwa model pembelajaran learning cycle 5e memiliki pengaruh yang signifikan terhadap hasil belajar IPA siswa.

Penggunaan media video dalam pembelajaran merupakan hal baru bagi siswa. karena sebelumnya siswa selalu belajar dengan menggunakan media yang berasal dari buku. Sehingga adanya media video dapat menarik perhatian siswa dalam belajar. Adanya media video juga dapat memudahkan guru dalam menyampaikan materi pembelajaran (Kadek, dkk, 2016). Secara otomatis, media video dapat memberikan dampak positif dalam pembelajaran yang mana siswa menjadi aktif dalam pembelajaran dan dapat berpengaruh pada sikap sosial siswa. Sejalan dengan pendapat Agustiningsih (2015) menyatakan bahwa media video dapat menarik perhatian siswa dan motivasi siswa dalam belajar, sehingga siswa menjadi antusias dalam mengikuti pembelajaran. Keaktifan siswa dalam pembelajaran ini tentu akan berpengaruh pada sikap sosial siswa seperti adanya sikap peduli, percaya diri yang meningkat, dan lain sebagainya.

Berdasarkan hasil analisis dan diperkuat oleh penelitian lain yang sesuai dengan penelitian ini, maka dapat disimpulkan bahwa terdapat pengaruh model cycle 5e sikap sosial siswa kelas IV SD Gugus V kecamata melaya Tahun Pelajaran 2019/2020.

\section{KESIMPULAN}

Berdasarkan hasil penelitian dan pembahasan, rata-rata nilai sikap sosial kelompok siswa yang dibelajarkan dengan model pembelajaran Cycle $5 E$ berbantuan media Video lebih tinggi dibandingkan kelompok siswa yang dibelajarkan dengan model pembelajaran yang diterapkan guru pada siswa kelas IV di SD Gugus V Kecamatan Melaya. Hasil hipotesis menunjukkan $t_{\text {hitung }}$ lebih besar dibandingkan $t_{\text {tabel }}$ sehingga $\mathrm{H}_{0}$ ditolak dan $\mathrm{H}_{1}$ diterima. Maka dapat disimpulkan terdapat pengaruh model pembelajaran Cycle $5 E$ berbantuan media Video terhadap sikap sosial siswa kelas IV SD gugus V Kecamatan Melaya Tahun Pelajaran 2019/2020. Disarankan kepada siswa agar lebih aktif dalam mengikuti pembelajaran, mampu menggali pengetahuan yang dimiliki secara mandiri ataupun berkelompok. Para guru agar lebih inovatif dalam memilih model pembelajaran dan media pembelajaran yang akan diterapkan pada proses pembelajaran. Kepada sekolah agar dapat menciptakan kondisi yang mampu mendorong para guru untuk mencoba menerapkan model pembelajaran Cycle $5 E$ berbantuan media Video dalam upaya meningkatkan sikap sosial. Di samping itu, bagi peneliti lain, penelitian ini dapat dijadikan referensi terhadap penelitian yang akan dilaksanakan. 


\section{DAFTAR PUSTAKA}

Agustiningsih. (2015). Video sebagai Alternatif Media Pembelajaran dalam Rangka Mendukung Keberhasilan Penerapan Kurikulum 2013 di Sekolah Dasar. Pancaran, 4(1), 55-68.

Ahmadi, A. H. (2007). Psikologi Sosial. Rineka Cipta.

Alessi, S. M., \& Trollip, S. (2001). Multimedia for learning: methods and development. Massachusets: A Pearson Education.

Astriani, Dyah, dkk. 2016. "Model Pembelajaran Learning cycle 5e: Mengaktifkan Siswa Pada Materi Suhu Dan Perubahannya". JPPIPA, Vol.1, No.2, (hlm. 71-75).

Asthira, I. W., Kusmariyatni, N., \& Margunayasa, I. G. (2016). Pengaruh model pembelajaran Learning Cycle "5e" terhadap hasil belajar IPA siswa kelas V di gugus III. E-Journal PGSD Universitas Pendidikan Ganesha., 4(1), 1-9.

Astriani, D., \& Istiqomah, N. N. (2016). Model Pembelajaran Learning cycle 5e: Mengaktifkan Siswa Pada Materi Suhu Dan Perubahannya. Jurnal Penelitian Pendidikan IPA, 1(2), 71-75.

Astuti, M. J., Haris, I. A., \& Tripalupi, L. E. (2019). Pengaruh Model Pembelajaran Learning Cycle (Siklus Belajar) 5 Fase Terhadap Keterampilan Sosial Siswa Pada Mata Pelajaran Ips Siswa Kelas Vii Smp Negeri 2 Seririt. Jurnal Pendidikan Ekonomi Undiksha, 11(1), 164. https://doi.org/10.23887/jjpe.v11i1.20110

Batubara, Hamdan H. dan D. Noor Ariani. "Pemanfaatan Video Sebagai Media Pembelajaran Matematika SD/MI". Jurnal Madrasah Ibtidaiyah, Vol.2, No.1 (hlm. 47-66).

Cakra, G. (2015). Pengaruh penggunaan metode pembelajaran bermain peran terhadap sikap sosial dan kemampuan berbicara bahasa Indonesia siswa kelas VI SD N 29 Dangin Puri tahun pelajaran 2014/2016. e-Journal Program Pascasarjana Universitas Pendidikan Ganesha. 5 (1). 1-10

Candiasa, I. M. (2010). Statistik univariat dan bivariat diserati dengan aplikasi SPSS. Singaraja: Unit Penerbitan IKIP Singaraja.

Dantes, N. (2007). Metode penelitian. Singaraja: Universitas Pendidikan Ganesha.

Dewi Virani, D. (2016). Deskripsi Sikap Sosial Pada Siswa Kelas 4 SDN Panarukan Kecamatan Buleleng AKbupaten Buleleng. E-Journal PGSD Universitas Pendidikan Ganesha, 4(1), 1-11.

Ditriguna, I. (2012). Pengaruh Model Pembelajaran Learning cycle 5e Terhadap Sikap Ilmiah dan Hasil Belajar IPA Siswa di Kelas V SD Negeri 5 Pendung.

Johari, Andriana, dkk. (2014). "Penerapan Media Video Dan Animasi Pada Materi Memvakum Dan Mengisi Refrigeran Terhadap Hasil Belajar Siswa". Journal of Mechanical Engineering Education, Vol. 1, No. 1.

Kadek, N., Dewi, R., Tastra, I. D. K., \& Pudjawan, K. (2016). Pengembangan Video Pembelajaran Berbasis Kearifan Lokal Mata Pelajaran Bahasa Bali Untuu Siswa Kelas III. E-Journal Edutech Universitas Pendidikan Ganesha Jurusan Teknologi Pendidikan, 5(2), 1-10.

Kementrian pendidikan dan kebudayaan. (2015). Panduan Penilaian untuk Sekolah Dasar(SD). Jakarta : direktorat jenderal pendidikan dasar dan menengah

Koyan, I. W. (2012). Statistik pendidikan teknik analisis data kuantitatif. Singaraja: Universitas Pendidikan Ganesha Press. 
Kuriniasih, I., \& Sani, B. (2014). Sukses mengimplementasikan kurikulum 2013. Kata Pena.

Mahadewi, L. P., \& dkk. (2012). Media video pembelajaran. Singaraja: UNDIKSHA PRESS.

Nia Wijayanti, N. W., Gading, I. K., \& Parmiti, D. P. (2018). Pengaruh Model Make A Match Berbantuan Peta Pikiran Terhadap Sikap Sosial dan Kompetensi Pengetahuan IPS. Jurnal Pendidikan IPS Indonesia, 2(2), 66-74. https://doi.org/10.23887/pips.v2i2.2891

Noviantari, P. S. (2015). Penerapan Model Pembelajaran Learning cycle 5e Berbantuan LKS Terstruktur Untuk Meningkatkan Kemampuan Penalaran Dan Komunikasi Matematika. Jurnal Santiaji Pendidikan, 5(2), 158-170.

Sanjiwana, P. P. C. M., Pudjawan, K., \& Margunayasa, I. G. (2015). Analisis sikap sosial siswa kelas V pada pembelajaran dengan kurikulum 2013. Mimbar PGSD Universitas Pendidikan Ganesha, 3(1). https://doi.org/http://dx.doi.org/10.23887/jjpgsd.v3i1.5631

Septiana, Elies Sari, Asim, Y. (2006). Penerapan Model Pembelajaran Learning Cycle 5E Untuk Meningkatkan Aktivitas Dan Prestasi Belajar Fisika Siswa Kelas X-Keperawatan SMK Kesehatan BIM Probolinggo. 1-13.

Setiawan, I. W. P., Suartama, I. K., \& Putri, D. A. W. M. (2017). Pengaruh Model Pembelajaran Learning Cycle 5e Berbantuan Mind Mapping Terhadap Hasil Belajar Matematika. Mimbar PGSD Undiksha, $5(2), 1-11$.

Suartini,Sudana, S. (2014). PENGARUH PEMBELAJARAN PQ4R TERHADAP SIKAP SOSIAL DAN HASIL BELAJAR IPS SISWA KELAS V SD DI DESA BONTIHING. 1.

Supriyana, Sukadi, S. (2020). EFEKTIVITAS IMPLEMENTASI KURIKULUM 2013 MATA PELAJARAN PPKN PADA SMA NEGERI DI KECAMATAN BUSUNGBIU. 8(1), 35-46.

Tegeh, I. M. (2015). Media pembelajaran. Universitas Pendidikan Ganesha.

Tegeh, I Made, Simamora, A. H., \& Dwipayana, K. (2019). Pengembangan Media Video Pembelajaran Dengan Model Pengembangan 4D Pada Mata Pelajaran Agama Hindu. Julnar Mimbar Ilmu, 24(2), 158-166.

Tiara, S. Kandita dan E. Yuliana Sari. 2019. "Analisis Teknik Penilaian Sikap Sosial Dalam Penerapan Kurikulum 2013 Di SDN 1 Watulimo". Jurnal Pendidikan Dasar, Vol. 11, No. 1 (hlm. 21-30).

Tuna, A., \& Kacar, A. (2013). The effect of 5E learning Cycle model in teaching trigonometry on students' academic achievement and their permanence of their knowledge. International Journal on Trends and Their Implications.

Utami, Yekti. (2018). "Penanaman Sikap Sosial Melalui Pembelajaran IPS Pada Siswa SMP Islam Sudirman Ambarawa Kabupaten Semarang". Sosiolium, Vol. 1, No.1 (hlm. 40-52). 